\title{
Study on Urban Agglomeration and Land Use Efficiency in China
}

\author{
Tianyu Liu ${ }^{1, a,{ }^{*},}$ Tianshan Liuº \\ ${ }^{1}$ School of Economics and Management, Beijing Jiaotong University, Beijing, China \\ ${ }^{2}$ School of Economics and Management, Beijing Jiaotong University, Beijing, China \\ a16120547@bjtu.edu.cn, bltiansh@126.com, \\ ${ }^{*}$ Corresponding author
}

Keywords: Land use efficiency, Urbanization, Distance, Agglomeration.

\begin{abstract}
With the urban statistical data from 2000 to 2016, this paper witch focus on the relationship between geography and urban land use efficiency, proves that the current land policy has a great negative impact on urban land use efficiency. The greater the distance from a city to a large port (Hong Kong, Shanghai and Tianjin), the greater its negative impact on land use efficiency. The policy implication of this paper is that the relaxation of policy control and the realization of cross-regional re-allocation of construction land use rights can provide new impetus for the next round of China's economic growth. And the restriction of cross-regional re-allocation of construction land use rights may lead to both the lack of efficiency and the balance in the medium and long term.
\end{abstract}

\section{Introduction}

In order to achieve a balanced development of macroeconomic, the Chinese government proposed to take land policy into macroeconomic control for the first time in 2003. This policy has played a certain role in restraining the overheating of local economy and overheated investment in real estate. In order to ensure the number of cultivated land, the relevant departments implement strict management on construction land indicators. The construction site is more inclined to the central and western provinces. Overall, the Midwest is the labor outflow area. The government wants to hedge the direction of the population movement by changing the direction of land supply, giving more land supply to the labor outflow area, and limiting the supply of land to another one.

Today, international trade is increasingly serving the division of labor in international manufacturing industry, and the relative dispersion of port cities within different regions of a country is conducive to the balance of regional economic development. China's situation is the opposite, the coastline is not long relative to the territory, the main port cities are mainly concentrated in the eastern Yangtze River Delta, Pearl River Delta and the Bohai Bay region. Under the background of the main mode of international trade, the relative concentration of port cities plays a vital role in the economic activities, especially the agglomeration of manufacturing industry to the coastal areas. Generally speaking, economic agglomeration and regional balance are easy to be regarded as a pair of contradictions, and the balanced allocation of construction land index has become a policy means to pursue balanced development among regions. Therefore, it is necessary to test how much land use efficiency loss will be caused by the trans- region reallocation of construction land use rights, and whether the existing policies promote regional balanced development. China implemented the reform policy in 1978, and after 1994, the pace of economic opening up further accelerated. This process provides a very good experiment for investigating the relationship between geography and land use efficiency in the process of globalization, and also verifies the theory of "center periphery" of urban system in new economic geography.

\section{Organization of the text correct}

In the third section, we compared the level of population agglomeration with the level of economic agglomeration and the level of land agglomeration, and found that the population agglomeration level 
was far from the desired level; Then, we use the urban panel data to depict China's urban layout, as well as the relationship between geography and land use efficiency. We draw the corresponding conclusions and discussed relevant policies in the end.

\section{Empirical analysis}

\subsection{Comparison of Economic Agglomeration and Population Agglomeration}

In this paper, the Gini coefficient is used to measure the degree of urban scale:

$$
\mathrm{G}=\frac{T}{2 S(n-1)} \text {. }
$$

This paper chooses the Gini coefficient of the four variables of population, non-agricultural population, built-up area and urban GDP. Taking the Gini coefficient of the population as an example, where $G$ is the Gini coefficient of the population size; ${ }^{T}$ is the sum of the absolute values of the difference in the population of each of the 280 prefecture-level cities; $S$ is the 280 prefecture-level cities of the total population; $n$ is the number of selected cities. The value of $G$ is between 0 and 1 , and the closer the value is to 1 , the larger the difference in size between regions. The larger the scale of the city, when the value is 1 , indicates that all the population is in a city and the other urban population is 0 ; when the value is closer to 0 , the smaller the difference in size between regions, the more the size of the city, when the value is 0 , all the city's population is equal.

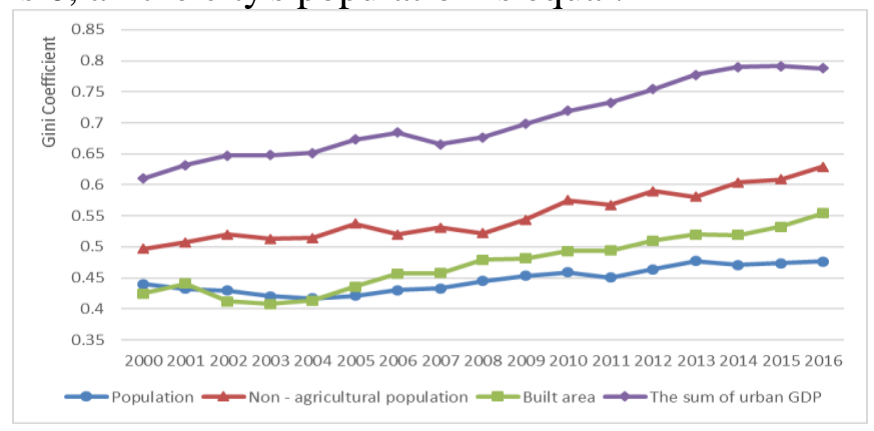

Fig. 1. Regional differences in urban scale in China (2000-2016)

Data sources: according to China City Statistical Yearbook

For a long time, the plight of urbanization in China is that the process of urbanization is far behind the process of industrialization. In recent years, China's urbanization process has accelerated. Since 2000, the difference in the size of urban population in China is basically on the rise, by 2016 the Gini coefficient rose to 0.47 , far from the world level. To see from the difference between the total GDP of the city, the size of the scale of Chinese cities is much higher than the difference in the size of the measurement. Moreover, the difference between the two is still expanding, with the pace of economic growth between Chinese cities far ahead of the population concentration. Even if we use only the urban non-agricultural population size difference as a measure, we still find that the gap between economic size and population size is widening. We look at the urban scale of the urban area of the difference, the result is that the size difference is higher than the urban population size difference, but lower than the non-agricultural population size differences. Although the difference in the built area has shown a rapid upward trend since 2003, the gap between GDP and GDP has not narrowed significantly.

\subsection{Comparison of Land Agglomeration and Population Agglomeration}

Compared with the urbanization in case of land and the one in case of population, the former is faster than the latter obviously. It can be seen from the table 1 that the average built-up area expansion rate of all urban samples in 2000-2016 years is $7.56 \%$ per year, while the growth rate of non-agricultural population in the same period is only $4.78 \%$, and the difference between them is $2.78 \%$. If the city 
sample is further divided into three parts: the East, the middle and the west. By contrast, it can be found that the difference between the growth rate of non-agricultural population and the expansion rate of built-up area is relatively small in the East, larger in the middle, and the biggest gap is in the west. In other words, the urbanization of population and land is basically synchronous only in the eastern cities. Considering that the population density of newly built built-up area is lower than that of the original urban area, the expansion rate of land area in the eastern built-up area is slightly faster than that of non-agricultural population, and the growth rate is also reasonable. In contrast, in the central region, the rate of land expansion in the built-up area is nearly 2 times that of the non-agricultural population, while in the West it is more than 2 times.

Table 1: Non-agricultural population growth and land area average annual expansion rate (2000-2016)

\begin{tabular}{ccccc}
\hline & National mean & Eastern mean & Median mean & Western mean \\
\hline $\begin{array}{c}\text { Growth rate of non - agricultural } \\
\text { population }\end{array}$ & 4.78 & 6.95 & 3.47 & 3.69 \\
\hline $\begin{array}{c}\text { Expansion rate of land area in } \\
\text { built-up area }\end{array}$ & 7.56 & 8.48 & 6.01 & 8.54 \\
\hline The difference & 2.78 & 1.53 & 2.54 & 4.85 \\
\hline
\end{tabular}

Data sources: according to China City Statistical Yearbook

From around three ports to about 500 kilometers away, the land use efficiency decreased from about 6 billion yuan to about 2 billion yuan (per square kilometer per year). Because of the measurement error of land interest rate efficiency itself, the more significant is the relative gap. Figure two shows that the land use efficiency drops from about $60 \%$ to about 500 kilometers from the three major ports to around 50 percent.

\subsection{Urban agglomeration and land use efficiency}

What are the differences in land use efficiency between cities with different geographical locations?

In this paper, the scatter map between geography and land use efficiency is drawn by using the section data of 2016. We define geography as the nearest distance from a city to the three ports of Hong Kong, Shanghai and Tianjin. We use a city built-up area per square kilometer average of two or three industry output (10000 yuan) to measure. That is, in the "Chinese City Statistical Yearbook" data provided by the city, the total land area is a very large changes in the data, so we do not according to this area to calculate land production efficiency, but also for the economic agglomeration, the agricultural land is of little significance to include. We will two or three industrial output divided by the area, assumes that the built-up area without agriculture, rather than the built-up area of no two or three, certainly there is a measurement error exists, but because of the two or three industry is mainly concentrated in the city area, therefore, the error is acceptable. In fact, there is no better way to measure the efficiency of land use. It can be seen from figure two that the distance and land use efficiency show Glass, the theoretical basis of this curve comes from the "center periphery" model of urban system.

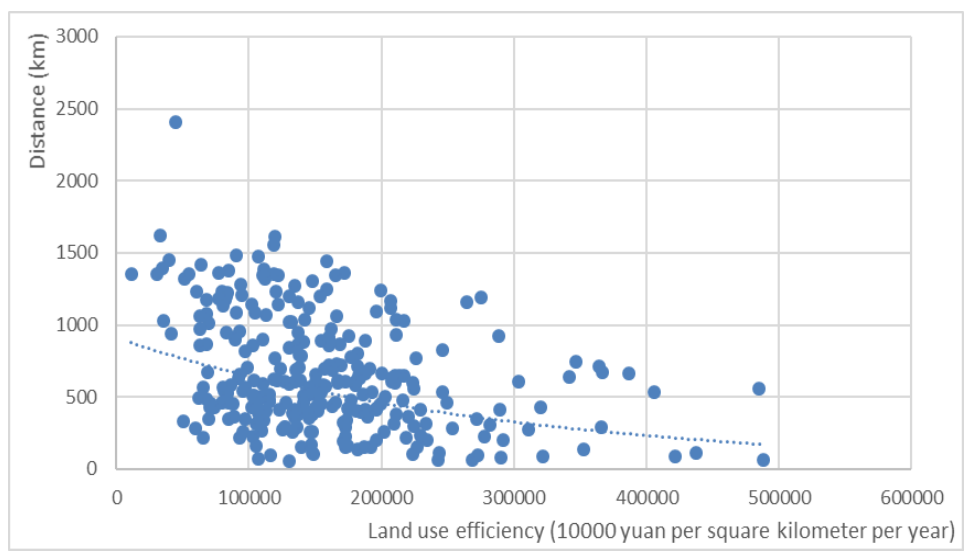


Fig. 2. Land use efficiency and distance from the port

Data sources: according to China City Statistical Yearbook

From around three ports to about 500 kilometers away, the land use efficiency decreased from about 6 billion yuan to about 2 billion yuan (per square kilometer per year). Because of the measurement error of land interest rate efficiency itself, the more significant is the relative gap. Figure two shows that the land use efficiency drops from about $60 \%$ to about 500 kilometers from the three major ports to around 50 percent.

\section{Conclusion}

Since 2000, along with the distance between inland cities of China to Hong Kong, Shanghai and Tianjin, the negative impact on urban land use efficiency has become larger and larger. In 2016, the city's land use efficiency was about $60 \%$ lower than that of the big port, about 500 kilometers from the big port. In the port within 450 kilometers, the expansion of city area to promote the land use efficiency, and further in the mainland, the expansion of city area has reduced the average land use efficiency.

Therefore, this paper argues that the promotion of economy and population in the process of urbanization to the coastal cities and the regional central cities in the mainland is the new driving force for the sustainable growth of China's economy in the next stage. China should not be bound by the goal of balanced development between regions. This is not to say that regional balance is not important. On the contrary, economic agglomeration can create conditions for balanced development both in the short run and in the long run. In China's regional development strategy, we should avoid the policy of restricting the flow of elements and unilaterally relying on fiscal transfer, resulting in efficiency and balance.

\section{References}

[1] Huanjun $\mathrm{Wu}$, Policy effect evaluation of land policy in real estate regulation [J]. Journal of Zhongnan University of Economics and Law, vol. 6, pp. 23-27+49+142-143, 2011

[2] Ming Lu, Trans - region reallocation of construction land use rights: a new driving force for China's economic growth [J]. World Economy, vol. 1, No. 34, pp. 107-125.

[3] Ming Lu and Zhao Chen, Why the land and the household registration system reform: based on the needs Chinese city and regional development theory and empirical research $[\mathrm{J}]$. Academic Journal, vol. 9, No. 41, pp. 78-84, 2009.

[4] Ming Lu, Jian Chen, In the process of balance: a "third way" for coordinated development of urban and rural areas [J]. World Economy, vol. 8, pp. 57-61, 2008. 